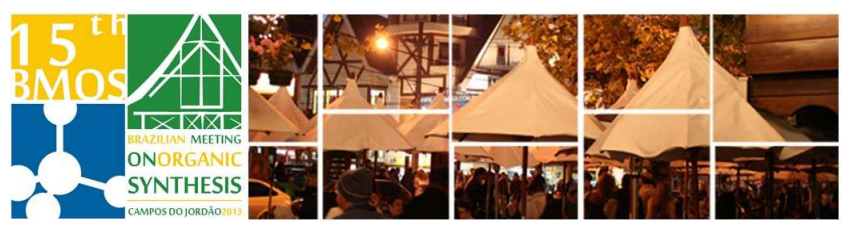

\title{
Selective oxidative aromatization of polyfunctionalized trifluoromethyl substituted chromenones by microwave
} irradiation

\author{
Susiane Cavinatto, Jussara Navarini, Carson W. Wiethan, Andrizia F. Junges, \\ Everton P. Pittaluga, Fábio M. Luz, Gisele R. Paim, Marcos A. P. Martins, Nilo \\ Zanatta, Helio G. Bonacorso*.
}

\begin{abstract}
Núcleo de Química de Heterociclos (NUQUIMHE), Departamento de Química, Universidade Federal de
\end{abstract}
Santa Maria, 97105-900 Santa Maria, RS, Brazil. *e-mail: heliogb@base.ufsm.br

Keywords: chromanes, microwave irradiation, aromatization

\section{INTRODUCTION}

The synthesis of fluoroorganic compounds is a challenging topic of the modern organic chemistry. Specially, the presence of trifluoromethyl moiety in the target molecule often results in significant changes of its physical, chemical and biological properties. ${ }^{1}$ In addition, chromenones are not only important biologically active compounds and natural products but also valuable substrates for the synthesis of related pharmacologically interesting compounds. In this context, we decided to study the oxidative aromatization of a series of trifluoromethylsubstituted chromenones, which we had been previously synthesized in our laboratory. ${ }^{2}$ Considering the importance of the heterocyclic precursors $\mathbf{1}$ and product $\mathbf{2}^{3,4}$ the aim of this work is to report the synthesis of series of high substituted chromane derivatives from the 2-trifluoromethyl-2Hchromenones (1) employing iodine/alcohol as an efficient and selective oxidative medium with microwave (MW) irradiation procedure.

\section{RESULTS AND DISCUSSION}

Since conventional procedures to obtain the compounds 2 requires a long reactional time, large amount of solvent and hard workup by column chromatography an oxidative aromatization reaction of 1 was also investigated using the microwave (MW) irradiation methodology. The reactions were performed in sealed vessels containing the substrates 1:iodine (1:2 molar ratio) in alcohol (3 $\mathrm{mL}$ ) and were submitted to microwave irradiation $(200 \mathrm{~W})$ for $0.5 \mathrm{~h}$ at a temperature of $100{ }^{\circ} \mathrm{C}$ and at 2.5 bar of pressure. After the reaction time, the mixture was transferred to a flask where the solvent was evaporated under reduced pressure and the residue was taken up into dichloromethane.The organic solution was sequentially washed with saturated aqueous sodium thiosulfate, sodium bicarbonate and brine and then dried over $\mathrm{Na}_{2} \mathrm{SO}_{4}$. The mixture was filtered and evaporated under reduced pressure (Scheme 1). All the products obtained were identified by NMR experiments and
GC/MS and comparison with the conventional methodology. ${ }^{5}$

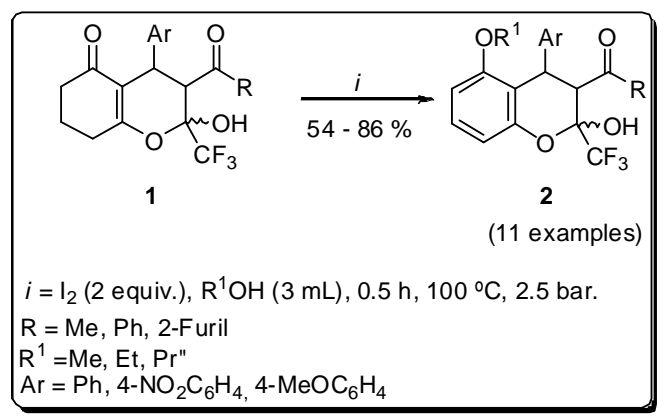

Scheme 1. Synthesis of chromane derivatives by MW.

\section{CONCLUSION}

In summary, we applied the well-known method of oxidative aromatization using iodine/alcohol now for the selective synthesis of trifluoromethyl-substituted chromanes (2) from the respective polyfunctionalized tetrahydro- $2 \mathrm{H}$-chromen-5(6H)ones (1). This synthesis was performed using microwave heating procedure, where it demonstrated advantages such as shorter reaction times, simplicity of the reaction, a reduced amount of solvent and good yields.

\section{ACKNOWLEDGEMENTS}

CNPq (Proj. \#s 470.788/2010-0 Universal and 303.013/2011-7) and FAPERGS (Proj. \#12/0982-1). Fellowships from CAPES and $\mathrm{CNPq}$ are also acknowledged.

\section{REFERENCES}

${ }^{1}$ (a) Chambers, R. D. Fluorine Org. Chem. Blackwell, Oxford, 2004; (b) Kirsh, P. Modern Fluoroorganic Chem., Wiley-VCH, Weinheim, Germany, 2004; (c) Begue, J. P.; Bonnet-Delpon, D. Bioorg. Med. Chem. Fluorine, Wiley, Hoboken, NJ, 2008; (d) Maienfish, P.; Hall, R. G. Chimia 2004, 58, 93; (e) Liu, Z. P. Current Org. Chem. 2010, 14, 888; (f) Mikami, K.; Itoh, Y.; Yamanaka, M. Chem. Rev. 2004, 1, 104.

2 Bonacorso, H.G.; Navarini, J.; Wiethan, C.W.; Bortolotto, G.P.; Paim, G.R.; Cavinatto, S.; Martins, M. A. P.; Zanatta, N.; Caro, M.S.B. J. Fluorine Chem. 2010, 132, 160.

${ }^{3}$ Mphahlele, J. M.; Moekwa, B. T. Org. Biomol. Chem. 2005, 3, 2469.

${ }^{4}$ Rueping, M.; Sugiono, E. E. Merino, Chem. Eur. J. 2008, 14, 632.

${ }^{5}$ Bonacorso, G. H.; Navarini, J.; Wiethan, C. W.; Andrighetto, R.; Junges, A.

F.; Cavinatto, S.; Martins, M. A. P.; Zanatta, N. J. Fluorine Chem. 2012, $142,90$. 